\title{
UNIVERSITY OF GLOUCESTERSHIRE
}

This is a peer-reviewed, post-print (final draft post-refereeing) version of the following published document and is licensed under All Rights Reserved license:

\section{Li, Ying ORCID: 0000-0003-4296-2753 and Mell, lan (2019) Understanding Landscape: Cultural Perceptions of Environment in the UK and China. In: Planning Cities with Nature. Cities and Nature. Springer Nature Switzerland AG, Cham, Switzerland, pp. 3-16. ISBN 9783030018658}

Official URL: http://dx.doi.org/10.1007/978-3-030-01866-5_1

DOI: http://dx.doi.org/10.1007/978-3-030-01866-5_1

EPrint URI: https://eprints.glos.ac.uk/id/eprint/6547

\section{Disclaimer}

The University of Gloucestershire has obtained warranties from all depositors as to their title in the material deposited and as to their right to deposit such material.

The University of Gloucestershire makes no representation or warranties of commercial utility, title, or fitness for a particular purpose or any other warranty, express or implied in respect of any material deposited.

The University of Gloucestershire makes no representation that the use of the materials will not infringe any patent, copyright, trademark or other property or proprietary rights.

The University of Gloucestershire accepts no liability for any infringement of intellectual property rights in any material deposited but will remove such material from public view pending investigation in the event of an allegation of any such infringement.

PLEASE SCROLL DOWN FOR TEXT. 


\title{
Understanding landscape: cultural perceptions of environment in the UK and China
}

\author{
Ying $\mathrm{Li}^{1}$ and Ian Mell${ }^{2}$
}

\begin{abstract}
Different philosophical traditions in China and the UK have contributed to the establishment of a multi-dimensional discussion of perceptions of nature. This has influenced the approach of landscape architects and planners to the design and planning of the built environment, and continues to affect the treatment of private and public space design. With rapid urbanisation in the twentieth century there has been a growing discussion (emanating from North America but also permeating discussions in the UK, Europe and more recently East Asia) of how we create places that satisfy the need and desire from the public for contact with 'nature'. This chapter presents a comparative discussion of historical perceptions of landscape within urban development located within the UK and China. We reflect on how urban ecology has been integrated into development practices, debate the interaction of people with urban landscape and consider responses to demands for nature in cities. The chapter concludes with a review the current practice surrounding the development and management of urban public space in China and the UK, reflecting the cultural context of nature in cities and the work of urban planning and design authorities.
\end{abstract}

\section{Introduction}

How we view the landscapes around us is dependent on who we are, where we are from and our understanding of the functions and values we attribute individually and societally to the environment. No two people view the landscape in the same way, which leads to discussions, negotiations and often conflicts between which physical, and communal elements of a location are considered important (Tuan, 1990). Variation is exacerbated by spatial influences with residents of different cities, countries and cultures seeing the landscape differently. Moreover, there is fluidity in the impact of temporal change on perceptions of the environment. Adding further complexity to this process is the ongoing debate between what is 'natural' and what is 'man-made'? Consequently, we see significant differences in how people of different ages, ethnicities and from different countries manage the natural landscape (Herrington, 2009).

Such variation is embedded within the research focussing on landscape perceptions and allows us to discuss the links between people, place and nature. This includes reflections on cultural associations with the landscapes, which are particularly strong in parts of Europe, as well as more economic readings of the environment associated with agriculture as productive landscapes. Moreover, in many countries including the UK, China and USA we can identify consensus focussing on what meanings landscapes hold within the wider community (Mell,

\footnotetext{
${ }^{1}$ Birmingham School of Architecture and Design, Birmingham City University, Birmingham, B4 7BD ying.li@bcu.ac.uk

2 School of Environment, Education \& Planning, University of Manchester, M13 9PL, UK ian.mell@manchester.ac.uk / +44 (0161) 2756868
} 
2016). These interpretations have been central to our understanding of landscape planning, and have shaped the ways in which the environment has been discussed in praxis.

The following chapter addresses these issues, reflecting on interpretations of landscape in China and in the UK. Although geographically, socially and in development terms very different, each has a tradition of landscape understandings that has shaped the ways in which rural and urban environments have been developed and managed. To examine these differences the following chapter asks how ecological thinking has been embedded within urban planning, and concludes by outlining how divergent discussions of landscape can be aligned to provide planners, developers and environmental professionals with scope to create and manage places that are aesthetically pleasing, culturally vibrant and ecologically functional.

\section{People, perceptions and place: interactions with nature in cities}

The scope of the word 'nature' is wide. Lovejoy (1935) distinguished sixty-six meanings of 'nature' following the philosophy of the ancient Greeks to the philosophies of the eighteenth century. In this chapter, the meaning of nature focuses on the changing interpretation of or the 'the natural world', and the ways in which it is viewed, used and valued by society, and how this has evolved over time as we have become more philosophical regarding the role of landscape in shape the functionality of our urban areas. meaning 'that which is not the man', unless stated otherwise. The antecedents of this process can be traced to the philosophical debates developed in ancient Greece, in which philosophy was nature-centric, rather than focused on the actions of humans. Contributions to this discussion in ancient China were alternatively based on the cultural foundation of agriculture and shaped the formation of its philosophy that man (little cosmos) and nature (great cosmos) were both correlated with 'natural' features. Therefore, human behavior was considered as part of the meaning of nature (Chen, 1989). Western philosophers, however, historically presented nature as excluding humans in terms of presenting it as dichotomy between the physical landscape and human activity, control or understanding of the environment. This is in direct contrast to the symbiotic human-nature relationship promoted by the Chinese sense of nature and was aligned to the growing use of scientific method to analyses the ways in which 'nature' functioned during the Enlightenment. These different perceptions of nature invariably influenced how people understand and deal with the built environment in China and the UK at various scales and through different mediums.

Western ideas regarding the relationship between man and nature have, however, changed more significantly and continue to change. Historically the predominant view was that 'nature' was something for humans to enjoy, exploit and take stewardship over; a view often located within Judeo-Christian narratives of landscape (Pepper, 1996). In the eighteenth century the natural world was increasingly seen both as part of God's creation and a source of beauty. In more contemporary discussions nature has been presented as being influenced more directly by science, shifting away from the natural world as being 'created' to one produced by 'the laws of nature' (Nassauer, 1995). The laws of nature came to be studied by scientists and the concept of 'natural law', associated with the classical scientific world, became central to the 'Whig'(British political party with anti-monarchy and anti-relgious groundings) politics, which dominated British politics between the 1680s-1850s (Champion, 2013). Therefore, although 
many western philosophers promoted a separation of man and nature, following the Enlightenment the rationality of scientific enquiry moved the emphasis towards experimentation, rationality and a more symbiotic relationship between humans and nature (Pepper, 1996).

Moving forward, discussions of landscape in the UK have been shaped by its relationship with the arts. This shifted the emphasis away from the biblical, although William Blake's 'And did those feet in ancient times' (also known as Jerusalem) balanced a Christian rhetoric towards nature with a culturally-focussed discourse on societal change (Sturzaker \& Mell, 2017). The influence of the landscape aesthetic of the late 1700's and early 1800's therefore influenced how landscapes were, and continue to be viewed, engaged with and managed. This purely aesthetic approach to landscape has in some cases diminished the ecological value of the environment and led to a duality of management practices, which could be considered manmade (Matless, 1998). For example upland areas of the UK, such as those in the Lake District managed for livestock farming are one such case where landscape management practices have systematically changed the physical and socio-cultural context of the landscape but is deemed by many as a 'traditional' form of management (Bateman et al., 2002).

Furthermore, in Lowenthal's (1985) discussion of landscape he notes that our interpretations of what is culturally acceptable land use evolves over time. Furthermore, he argued that a process of nostalgia becomes a complicit aspect of how we moderate our perceptions of the landscape, as although the past is a "foreign country", many people seem unable or unwilling to accept change to the landscape as an inevitable part of life. Matless takes Lowenthal's thesis further arguing through Daniels that any discussion of landscape holds a duplicity because of the inherent variation in the form, structure and interpretation of these locations (Daniels, 1989 in Matless, 1998:12). The ways in which such duplicity is played out can be seen in the variation of landscape planning discussions across the UK.

For example, around many of the UK's post-industrial cities there is a growing call for investment in landscape improvement to address the dereliction associated with industrial decline. England's Community Forests and Natural England, as well as the Environmental Agency and Wildlife Trust, have been key actors in this process (Mell, 2016). However, in rural areas in the UK there is an alternative discussion demanding retention of the 'status quo' for landscape. Many communities (and indeed politicians and decision-makers) appear aligned with this second argument claiming that the perception of the landscape aesthetic is more important that providing housing, transport or employment infrastructure for local people (cf. Campaign for the Protection of Rural England \& Natural England, 2010). This argument is most often debated in relation to the green belt, which has been considered sacrosanct since the late 1950's and remain one of the few planning policies to withstand changes of government. Within the green belt a rhetorical examination of landscape value exists, which is not necessarily related to the physical characteristics of the location (Sturzaker \& Mell, 2017). Moreover, where developers and planning consultants try to circumvent green belt policy they claim that its ecological or socio-cultural value are overstated (Amati \& Taylor, 2010). This illustrates the complex contestations associated with our interpretations of the landscapes around us. It also highlights that even if we are aware of the ecological, socio-cultural and economic composition (or value) of a landscape in the UK that our individual and communal perceptions of it are malleable (Matless, 1998). 
Placing this discussion is historical context we can reflect on how at the end of the 19th century the Garden City movement was a key advocate of incorporating 'nature' into cities (Howard, 1989). However, in McHarg's (1969) Design with nature he postulated the view that western understandings of landscape was based on a combination of Christian control, stewardship or appreciation of natural systems. He also praised Buddhism's interactional relationship between people and the environment suggesting that nature was respected to a greater extent in Asia. Since McHarg presented this thesis rapid development has occurred in Asia, leading scholars to argue that "nature" and its management are being placed under excessive pressures; more so than in Europe or North America, thus challenging the symbiotic relationships between humans and nature. Philosophically this reflects the repositioning of man as a part of nature, which promotes the view that there is no need for nature to have special protection (Chen \& Wu, 2009).

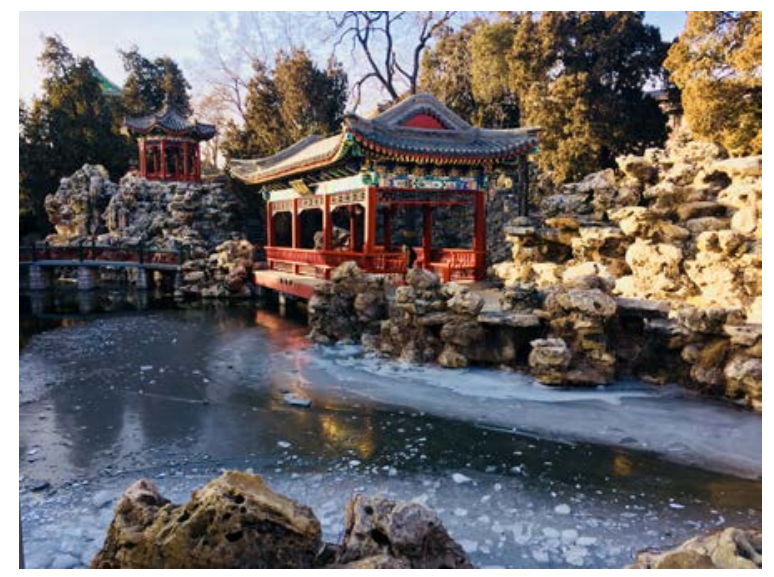

Figure 1 The Jing Xin Zhai (Tranquil Heart Studio) in Beihai Park illustrates the way in which 'nature' is understood in Chinese culture: it includes water, stone, plants, wood and metal (Source: Ying Li).

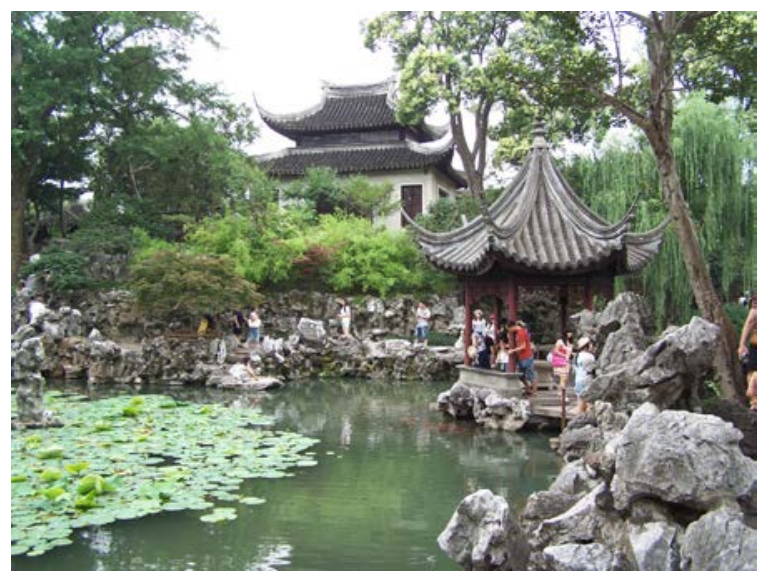

Figure 2: The Lion Forest Garden is a World Heritage Site based on its classical Chinese garden designs that integrates water, mountains, air, buildings and people (Source: Ian Mell).

For example, in China, the philosophical integration of man and nature (天人合一 : tianrenheyi) demonstrates a holistic approach to the relationship between "heaven and earth" 
(天: tian and 地 : di ). Tian presents Yang and earth presents Yin, as explored by the Chinese philosopher Laotzu who stated:

The ten thousand things carry shade

And embrace sunlight.

Shade and sunlight, yin and yang,

Breath blending into harmony

(Addiss and Lombardo, 2007 p.42)

Chinese translation: 万物负阴以抱阳, 冲气以为和

Yin-yang philosophy has been used to understand the fundamental methodology and philosophy of what we now call 'ecosystems' (Chen \& Wu, 2009). Within this the role of the sun, water, and energy illustrate the circulation of the earth, and the formulation of wind, cloud, rain, snow (i.e. the climate), as well as the formation of surface water and the groundwater cycle (Wu, 2015). Thus, the philosophical view of landscape is of a larger integrated and interactive natural system that permeates all parts of life. This philosophical assessment can also be applied at discreet scales. At a city scale, Fengshui theory was widely used in ancient China for planning the built environment and is closely linked to Taoism and the creation of a harmonious relationship between man and the surrounding environment (Shang, 1992). Moreover, at the small scale, the idea of nature in Chinese garden design is derived from the appreciation of 'Shan-Shui Hua' (mountain-water painting), associated with both Taoism and Buddhism. Classical Chinese garden designers aimed to use gardens to 'imitate Shan Shui' (Sullivan, 1984), which is reflected in the ways that artificial mountains and water system often appear in Chinese landscape architecture (Fig.1). This highlights a more holistic approach to the design of a Chinese yuan (gardens) as it reflects the combination of the basic elements of design: vegetation, landform, and water that are important but also the creation of a world that promotes a harmonious integration between man and nature (Fig.2).

\section{The role of ecology in urban planning}

Throughout the twenty-first century there has been a growing call for the continued introduction of nature in cities. In these cases, nature has been used to provide opportunities for people to interact with and gain benefits from ecological and water resources in urban areas. Moreover, Keller (2012) argued that human behavior is connected with nature and that changes to the physical structure of our cities, as they become more rigid, greyer and less interactive, challenges our ability to navigate, interact and find value in urban landscapes. However, there is a wealth of evidence stating that people continue to value nature and that such ongoing support of investment in private gardens, public green space, and the promotion of landscapes within our social consciousness is a key indicator of quality of life (Kaplan, 1989). Consequently, it has been argued that contact with nature should be a fundamental aspect of the design of an urban area, as Kaplan \& Kaplan (1989, p. 1) wrote:

Nature is a valued and appreciated part of life. Examples abound. People plant flowers and shrubs and nature house plants; cities invest heavily in trees; 
citizens band together to preserve natural settings they have never seen; landscapes for centuries have been the subject of painting and poetry. Nature seems to be important to people.

The benefit of nature for people in urban areas are however not only physical but also physiological with Milward and Mostyn (1980, p. 29) arguing that:

The benefits for those who work on or make use of a natural wildlife area fall into four categories: emotional; intellectual; social and physical; of which the most important is the emotional benefit.

This suggests that the design of green space not only provides physical facilities but should also connect people psychologically with nature; a view that has been embedded within landscape architecture and green space planning in both Asia and Europe (Mell, 2016). Thus, we can use McMichael's (2005) call to arms that fresh air, clean water, flora, and animals are basic needs in people's daily lives and promotes what McHarg called 'design with nature'. (McHarg, 1969). However, the on-going process of urbanization being witnessed globally has disturbed, and in many places, reduced the percentage of natural spaces within urban areas. The result of which is that urban green spaces are becoming rarer yet their value to urban populations through access to parks, gardens, and allotments remain critical factors in promoting a high quality of life (Dehaene and Cauter, 2008).

To inform this process the study of urban ecology has grown in prominence highlighting how the relationships between humans and nature can be managed to improve the quality of the socio-economic and ecological environment (Shulenberger, 2008). In support of this Lynch and Hack (1984) argued that they regarded ecology as the second criterion in urban green space design, the first being to supply humans with the opportunity to experience nature. Thus, high quality public green and open space should offer 'psychological openness' and "ecological continuity” in urban areas (Lynch \& Hack, 1984 p.77). There is also a growing literature promoting the added contribution of urban green spaces to the physical and psychological health of the people who use it (Coutts, 2016). Furthermore, in addition to facilitating human health, green space can also generate economic benefits to property. Research by Jim \& Chen (2006) and Mell et al. (2016) suggest that proximity to high quality green space is one of the determinants of the value of a property in cities. Extending this argument Bishop (2005) highlights that the closer homes or businesses are to high quality green space the more expensive they will be. Similarly, urban biodiversity plays a significant role in the design and planning of our cities (Richter, 2011),and help to ensures the conservation of different species at a local level promoting diversity in urban areas. It also promotes interactions between biodiversity and humans which can help people, especially children and older people, connect with nature (Muller, 2010).

\section{Current practice of landscape investment in urban development practice}

Ecology, as a central concept in landscape design and planning, does not have a long history in 
modern China and is not tied to historical understandings of nature (Mars \& Hornsby, 2008). Where "urban ecology" has been used, it is in relation to western assessments and interactions with Chinese landscapes. The first Specialty Committee on Urban Ecology (SCUE) was held in 1984 at the Second Conference of the Ecological Study of Urban Areas (Chen, 1989). However, Chinese research concerning ecology remains predominately imported from western countries (Wang, 2005). Following the rapid development of urban areas from the 1990s onwards political commitments were made by the Chinese government to ensure urban ecology was integrated into development (Song, 2008). In 2007, the importance of ecology was for the first time reported at the highest official level. The Chinese President Hu Jintao stated to the $17^{\text {th }}$ National Congress of the Chinese Communist Party that China needs to build an economy based on eco-civilization (Hu, 2007). This included making changes to industrial structures, development modes, and consumption patterns to promote energy conservation and ecologically environmental protection (Clark, 2009).

In addition to urban ecology a growing number of researchers have started to engage with the concept of green infrastructure in China. Chinese green infrastructure has not, however, been planned with full consideration of biodiversity. Urban squares, parks and other public spaces are not constructed as 'ecological' locations but are often simply large areas of grass. Compared to the UK, there are fewer natural and ecological areas in Chinese cities and nature conservation continues to receive limited attention from government. Richter and Weiland (2011, p. 69) extend this, stating that:

It is argued that 'population-speculation-land use-infrastructure layout' has been proven invalid in dealing with the swiftness of urban development issue and is largely responsible for the degradation of ecological conditions and the chaotic situation of the current Chinese cities

Post-1978, when China 'opened up' to the west, it has started to engage with these approaches to policy-making and design and adapted them into Chinese contexts. We can therefore argue that European landscape urban design and planning models have been effectively imported to China, and the 'ecology concept' has started to appear in academic and government circles leading to a great number of development projects labeled as garden, eco, sponge and forest cities (Zhang et al. 2012).

With rapid urbanization and a growing concern for ecological capacity, new eco-city projects have been planned in China. Through international collaboration with private partners a series of eco-city projects were designed including Sino-United Kingdom Dongtan Eco-City in Shanghai, Caofeidian Eco-City in Tangshan, Sino-Swedish Wuxi Eco-City, Sino-Finland Mentougou Eco-Valley in Beijing, and the Sino-Singapore Tianjin Eco-City (Baeumler et al, 2012). The focus of each eco-city varied, however, all employed an overarching ethos of integrating nature into urban areas to ensure that ecological functions were maintained, and that people had opportunities to interact with the environment.

The first eco-city proposed in 2005 was Dongtan, located on Chongming Island north-west of central Shanghai, designed by the London-based company Arup Group. Within the proposal of Dongtan Eco-city, the government planned two major landscape projects: Chongming Dongtan Nature Reserve and Pujiang Intelligence Valley promoting a harmonious integration 
of people and nature (Cherry, 2007). It was argued, however, that the ecological focus of Dongtan was insufficient to ensure nature was brought into the city, and alternatively proposed that the city conformed to more traditional economic development objectives (Sze, 2015). The implementation of Dongtan eco-city stalled in 2008 due of changing economic and political influences in China, and has not to date been restarted (Wu \& Gaubatz, 2013).

In addition to eco-cities Howard's Garden City (1989) concept has also been applied in urban regeneration practices in China. In 2009, the local government of Chengdu established the 'World Modern Garden City strategy, with a 20-year aim of establishing Chengdu as a world city within a 50-year time horizon (Chunsheng Li's speech in government conference, 2009). Based on the core philosophy of 'natural beauty, social justice, and urban-rural integration', the strategy aims to balance the interaction between urban areas and the countryside. The proposals for Chengdu Garden City were developed in consultation with representatives of the Letchworth Garden City Heritage Foundation: the first garden city. However, the density and physical architecture of the Tianfu district of Chengdu were less compatible with the Arts and Crafts style of construction required by Garden Cities. Thus, even in the early stages of developing the Chengdu Garden City proposals doubts were raised regarding the validity of investing in 'faux-western urbanism' and the lack of green infrastructure integrated into the process (Williams, 2017).

To summarise, the concept of nature in modern Chinese cities has moved away from traditional Chinese perceptions of nature, to one where western-based ecological concepts are identified as design "labels" rather than for the theoretical underpinning of ecological design. Thus, the main drivers of development remain economic rather than the creation of livable and sustainable cities per se.

In Europe, especially post-World War 2, the concept of ecology has helped cities like London re-engage with their natural environment (Fitter, 1946). Moreover, as new cities were developed they were planned to include a greater variety of flora and fauna in urban habitats (Fig 3). In 1950, Birmingham's land regeneration handbook was presented at the annual meeting of the British Association (Rees and Skelding, 1950), facilitating the study of urban ecology based on case studies of different cities throughout the UK and Europe. In London, the protection of wildlife sites began in earnest in the 1970s, and from 1982 the Greater London Authority (GLA) commenced on one of the most successful programmes of nature conservation, which has subsequently been embedded in the London Plan (Douglas, 2011).

In the UK, there is a longer association between green infrastructure planning, identified within the creation of Garden Cities, the promotion of sustainable communities, and the rejuvenation work of environmental organisations around England's former industrial cities (Mersey Forest, 2013). In Welwyn, Letchworth and Milton Keynes we can see the inclusion of Garden City ideals including the design of homes, areas of employment and links to amenities that utilize greenways and pedestrian-orientated travel (Town \& Country Planning Association, 2012). Thus, although relatively small, they reinforce social interaction with the landscape and nature. 


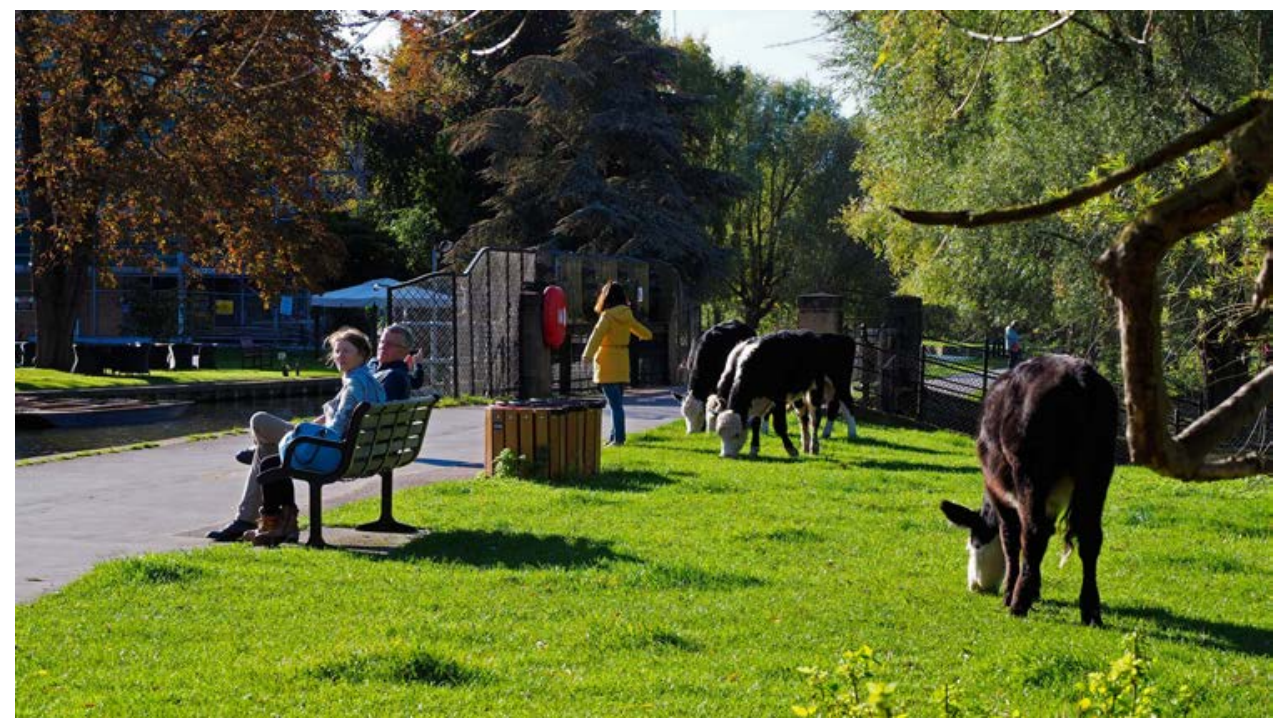

Figure 3: UK cities have had green space since the Middle Ages and it has usually been for functional purposes, like Sheep's Green and Lammas Land in Cambridge (Source: Ying Li)

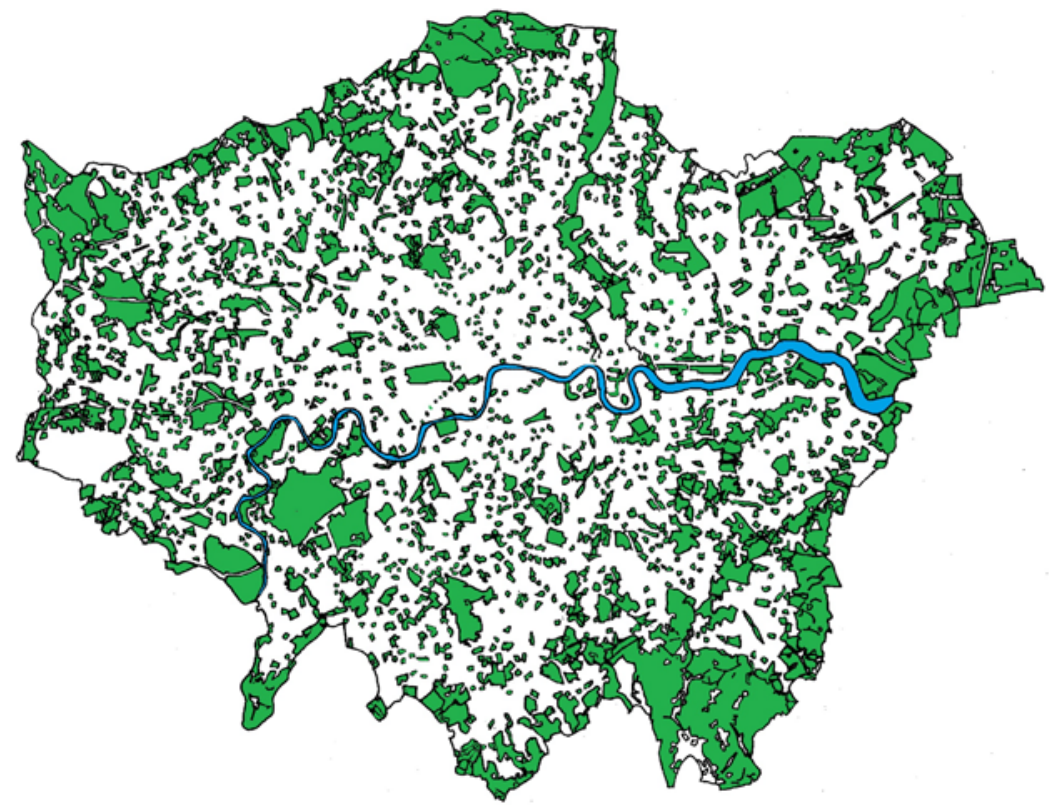

Figure 3: London has approximately 49\% green and blue infrastructure providing access to spaces for social and communal health, the development of economic activities, and climate change mitigation (Source: Ian Mell).

More recently we have seen extensive woodland creation and the use of green infrastructure around former industrial cities in England. This has been led by Natural England, the Woodland Trust and England's Community Forests establishing to a much greater level of engagement with former denuded landscapes (England's Community Forests \& Forestry Commission, 2012). Using play, forest schools and woodland planting the value of nature has been reinforced in local communities to promote a more active engagement with the landscape; the north-west of England between Manchester and Liverpool being frontrunners of these practices (Mersey 
Forest, 2013).

Both the creation of new woodlands and the inclusion of Garden City principles have assisted policy-makers and developers to promote the use of green infrastructure in the UK. This has refined the use of green infrastructure to address stormwater, biodiversity, health and well-being and recreational opportunity for people of all communities. Successes have been achieved through the increased inclusion of nature in school grounds (and through engagement with forest schools), the redesign of hospital grounds to include areas of reflection and engagement with nature, and in new housing development where sustainable drainage systems have been used to create biodiverse areas that also relieve surface water flooding (Ecotec, 2012; Mell, 2016). In addition, an adaptive use of street trees and urban greening has been seen to provide aesthetic, economic and ecological benefits (in terms of pollution interception/mitigation).

Each of these uses of green infrastructure in urban areas has been employed to meet the diverse uses, perceptions and understandings of nature by different people. Consequently, there has been a varied set of approaches taken by developers and decision-makers to ensure that nature is included in development debates. However, as in China this is not without its barriers, as political and economic variables have limited these practices in some locations.

\section{Conclusion}

China and the UK have rich and long traditions of designing their urban landscapes. However, they have different perceptions of nature that have influenced how it is incorporated into the consciousness of the public, academics and planners. This appears to have influenced the design of public and private space at all scales. Furthermore, although China has a history of planning with nature it has increasingly adopted practices from western cultures, as it opened-up to new development concepts. The more traditional models of planning in Chinese cities have not been carried forward and thus we have seen a lack of Chinese theories being embedded in contemporary landscape design. In contrast, some western theorists have taken aspects of eastern landscape philosophy and incorporated them into European and North American approaches to landscape management (cf. McHarg, 1969). Western theorists also pointed to the importance of considering people in landscape design and promoted a more people/naturecentered approach to development. This can be identified in current research examining the relationships between nature, health, and wellbeing. There does, however, remain a need for an integrated 'man and nature' approach to landscape and urban planning in both the east and the west.

\section{Bibliography}

Addiss A, Lombardo S (2007) TaoTe Ching Eastern Philosophy and Taoism Series. Shambhala Publications, Colorado, p 42

Amati M, Taylor L (2010) From Green Belts to Green Infrastructure. Planning Practice and Research 25(2): 143-155

Baeumler A, Chen M et al (2012) Eco-Cities and Low-Carbon Cities: The China Context and Global Perspectives. In: Baeumler (eds) Sustainable Low-Carbon City Development in China. World 
Bank, Washington, DC, p 33-62

Bateman IJ, Carson RT, Day B, Hanemann M, Hanley N, Hett T, Loomes G et al (2002) Economic valuation with stated preference techniques: a manual. Edward Elgar Publishing Ltd, London

Bishop I (2005) Visualization in Landscape and Environmental Planning. Routledge, Abingdon

Campaign for the Protection of Rural England, \& Natural England (2010) Green Belts: a greener future A report by Natural England and the Campaign to Protect Rural England. London

Champion J (2013) Republican learning: John Toland and the crisis of Christian culture, 1696-1722. Manchester University Press, Manchester

Chen CD (1989) Urban Ecology in China, Journal of Applied Ecology. British Ecological Society 26 (3): 875 - 877

Chen X, Wu J (2009) Sustainable landscape architecture: implications of the Chinese philosophy of “unity of man with nature” and beyond. Landscape Ecology 24(8): 1015-1026. dol: 10.1007/s10980-009-9369-1

Cherry S (2007) How to build a green city: Shanghai hopes to build the world's first truly sustainable city. https://spectrum.ieee.org/energy/environment/how-to-build-a-green-city. Accessed 21 Sep 2017

Clark WW (ed) (2009) Sustainable Communities. Springer-Verlag, New York

Coutts C (2016) Green Infrastructure and Public Health. Routledge, Abingdon

Daniels S (1989) Marxism, Culture and the Duplicity of Landscape. In Peet, R. \& Thrift, N. (1989)

(Eds.) New Models in Geography Vol 2: 236-255

Dehaene M, Cauter DL (2008) Heterotopia and the City: Public Space in a Postcivil Society. Routledge, Abingdon

Douglas I, Goode D et al (2011) The Routledge Handbook of Urban Ecology. Routledge, London Ecotec (2012) The economic benefits of Green Infrastructure: Developing key tests for evaluating the benefits of Green Infrastructure. Report for The Mersey Forest \& Natural Economy Northwest 1-32

England's Community Forests \& Forestry Commission (2012) Benefits to Health and Wellbeing of Trees and Green Spaces. Farnham.

http://www.communityforest.org.uk/resources/case_study_health_and_wellbeing.pdf Accessed 01 Nov 2017

Fitter RSR (1946) London’s natural history. Collins, Glasgow

Herrington S (2009) On Landscapes. New York, Routledge

Howard E (1989) Garden Cities of Tomorrow. S.Sonnenschein \& Co., Ltd, London

Hu JT (2007) Hold High the Great Banner of Socialism with Chinese Characteristics and Strive for New Victories in Building a Moderately Prosperous Society in all. In: Report to the Seventeenth National Congress of the Communist Party of China.

http://www.china.org.cn/english/congress/229611.htm. Accessed 10/10/2015

Jim CY, Chen W (2006) Recreation-amenity use and contingent valuation of urban greenspaces in Guangzhou, China. Landscape \& Urban Planning 75 (1-2): 81-96

Kaplan R, Kaplan S (1989) The Experience of Nature: A Psychological Perspective. Cambridge University Press, Cambridge

Kellert SR (2012) Birthright: People and Nature in the Modern World. Yale University Press, Connecticut

Lovejoy AO (1935) Some Meaning of Nature. In: A.O. Lovejoy (eds) A Documentary History of 
Primitivism and Related Ideas. Johns Hopkins Press, Baltimore, p 447-56

Lowenthal D (1985). The Past is a Foreign Country. Cambridge University Press, Cambridge

Lynch K, Hack G (1984) Site Planning, 3rd edn. MIT Press, Cambridge

McHarg I (1969) Design with Nature (Wiley Series in Sustainable Design). John Wiley \& Sons, New York

McMichael A (2005) Ecosystems and Human Well - Being: Health Synthesis: A Report of the Millennium Ecosystem Assessment. World Health Organization, Geneva

Mars N, Hornsby A (2008) The Chinese Dream: A Society Under Construction, 010 Publishers, Rotterdam

Matless D (1998). Landscape and Englishness. Reakton Books, London

Mell IC (2016). Global Green Infrastructure: Lessons for successful policy-making, investment and management. Routledge, Abingdon

Mersey Forest (2013). The Mersey Forest Plan: Final Draft, September 2013. Risley Moss

Milward A, Mostyn BJ (1980) Personal Benefits and Satisfactions Derived from Participation in Urban Wildlife Projects. Social and Community Planning Research on Behalf of the Nature Conservancy Council. Shrewsbury

Muller N, Werner P et al (2010) Urban Biodiversity and Design. Wiley, Blackwell

Nassauer J (1995) Culture and changing landscape structure. Landscape Ecology, 10(4), 229-237. dol:10.1007/BF00129257

Pepper D (1996) Modern Environmentalism: An Introduction. Routledge, London

Rees WJ, Skelding AD (1950) Vegetation. In: Wise MJ (ed) Birmingham and its Regional Setting: A Scientific Survey, Birmingham. British Association Local Executive Committee, p 65-7

Richter M, Weiland U (2011) Applied Urban Ecology: A Global Framework. Wiley, Blackwell

Shang K (1992) China’s Pattern of Fengshui: its formation, Relationship to Environment and landscaping. In: Wang QH (eds) Research of Fengshui Theory. Tianjin University Press, Tianjin, p 27

Shulenberger E, Endlicher W et al (eds) (2008) Urban Ecology: An International Perspective on the Interaction Between Humans and Nature. Springer, Berlin

Song YC, Gao J (eds) (2008) Urban Ecology Studies in China, with an Emphasis on Shanghai. Springer, New York

Sturzaker J, Mell I (2017) Green Belts: Past, Present \& Future. Abingdon, Routlegde

Sullivan M (1984) The Arts of China. University of California Press, Berkeley

Sze J (2015) Fantasy Islands: Chinese Dreams and Ecological Fears in an Age of Climate Crisis. University of California Press, Berkeley

Town \& Country Planning Association (2012) Creating Garden Cities and Suburbs Today: Policies, Practices, Partnerships and Model Approaches - A Report of the Garden Cities and Suburbs Expert Group. Town \& Country Planning Association, London

Tuan Y (1990) Topophilia: A Study of Environmental Perceptions, Attitudes, and Values. Columbia University Press, New York City

Wang C (2005) One China, Many Paths. Verso, London

Williams A (2017) China’s Urban Revolution: Understanding Chinese Eco-Cities. Bloomsbury Publishing, London

Wu F (2015) Planning for Growth: Urban and Regional Planning in China (RTPI Library Series). 
Routledge, New York

Wu WP, Gaubatz P (2013) The Chinese City. Routledge, Abingdon

Zhang SH, Roo GD et al (2012) China: What About the Urban Revolution? Rapid Transformations in

Chinese Planning and Its Links with a Slowly Emerging European Planning Theory. European Planning Studies, 20(12): 1977-2011 